\title{
La función de los consejos en el Poema de Alfonso Onceno: fortalecimiento del poder regio y ejercicio de la justicia*
}

\section{(1) Juan Harari}

Facultad de Filosofía y Letras - Universidad de Buenos Aires, Argentina Juanhar95@gmail.com

\section{Resumen}

Cuando en el Poema de Alfonso Onceno el rey decide intervenir para controlar a los tutores, su ayo le otorga consejos sobre el buen gobierno. En lo que respecta a la relación con sus vasallos, le aconseja ejercer justicia sin dejarse llevar por el "despecho". Se delinea allí un tipo de acción ejemplar: la templanza con los propios. Sin embargo, algunas de las acciones del rey frente a la nobleza parecen entrar en abierta contradicción con este modelo. Por eso, la hipótesis de este trabajo es que los consejos permiten presentar los casos más controversiales de la política interna bajo la forma de problemas relativos al ejercicio del gobierno. De ese modo, el poema pone de manifiesto las motivaciones y justificaciones que guían las decisiones del rey frente a cada problema particular. A través de este mecanismo, se le atribuyen al rey cualidades virtuosas vinculadas a la toma de decisiones y el cumplimiento de los deberes regios que permiten adecuar su figura al modelo delineado por el ayo. En esta forma de configurar la imagen del rey, es posible leer, entonces, el modelo de rey pacificador y justiciero que el poema pone en escena.

\section{The role of advices in the Poema de Alfonso Onceno: strengthening of} royal power and the exercise of justice

\footnotetext{
Abstract

When in the Poema de Alfonso Onceno the king decides to intervene to control the tutors, his ayo advises him on how to be a good governor. Regarding the relationship with his vassals, the ayo advises the king to exercise justice without being carried away by "spite." An exemplary type of action is proposed there: temperance with their own people. However, some of the king's actions against nobility seem to contradict this

* Agradezco a ambos árbitros los invaluables comentarios que me han hecho. Algunos han sido incorporados y otros, por su importancia, ameritan un desarrollo más amplio que el que permiten los límites de este artículo, tanto en lo que hace al recorte del corpus como en cuanto al espacio pautado por la revista.
}

Palabras clave Alfonso XI consejos ejemplaridad rey pacificador rey justiciero

Keywords

Alfonso XI advices exemplariness pacifier king righteous king 
1. Paquette ha señalado que casi todos los poemas épicos postulan dos grandes enfrentamientos, uno irreconciliable entre dos religiones (o entre pueblos o reinos) y otro que se da en el interior del grupo al que pertenece el héroe (quien a su vez puede sufrir también una crisis interna (Ver leanMarcel Paquette, 'L' épopée', en su Typologie des sources du Moyen Âge occidental, fasc. 49, Turnhout, Bélgica: Brepols, 1988, 17-35).

2. Para un estudio más general sobre las imágenes que podían proyectarse de los reyes en la Edad Media (rey juez, rey guerrero, rey mesías, rey pacificador, etc) es insoslayable la lectura de Nieto Soria (1989).

3. Seguimos la edición de Victorio, J. (ed.) (1991). Poema de Alfonso Onceno, Madrid: Ediciones Cátedra.

4. De hecho, cuando el ayo le señala al rey lo que debe hacer, ya no con sus vasallos, sino con otros reyes que pudieran afrentarlo, el consejo que le otorga es exactamente el inverso: "vengad el vuestro despecho" (PAO: estr. 138), lo cual indica que los consejos del ayo condensan dos modelos de comportamientos netamente diferenciados en lo que respecta a la política interna y la política externa. Para ver la relación de estos consejos con los dados por Aristóteles a Alejandro en el Libro de Alexandre puede leerse Catalán (1953), especialmente en los capítulos V y VIII. model. Therefore, the hypothesis of this article is that advices are used to present the most controversial cases of internal policy in the form of problems related to the exercise of government. In this way, the poem highlights the motivations and justifications that guide the king's decisions taken in front of each particular problem. Through this mechanism, virtuous qualities linked to decision-making and the fulfilment of royal duties are attributed to the king, which allow him to adapt his figure to the model proposed by the ayo. Then, in this way of constructing the royal image it is possible to read the model of the pacifier and righteous king that the poem presents.

\section{Justificar al rey: el dilema de los fines y los medios}

Si bien en el Poema de Alfonso Onceno (PAO) se destaca el accionar del rey en la campaña bélica contra los musulmanes, el texto respeta el esquema de doble misión del héroe que suelen presentar los poemas épicos. ${ }^{1}$ De este modo, el monarca deberá vencer primero a un conjunto de nobles castellanos hostiles, entre los que se cuentan sus viejos tutores y sus aliados, y luego a los granadinos y benimerines. Se trata entonces de una obra que, aunque tiene como objetivo principal alabar la campaña reconquistadora de Alfonso XI, también apunta a ser un texto propagandístico de su política interna.

Respecto de la legitimación de esa política en el poema, Rodríguez-Picavea señala que, desde la perspectiva de la obra, "todos los medios son válidos" para lograr la pacificación del reino frente a la nobleza anárquica "y el poeta los justifica en la medida en que contribuyen a ese fin" (2012: 190). Por eso, para este autor, la imagen del rey "pacificador y justiciero" es la de un rey que imparte justicia sobre todo de forma inclemente: se trataría de un rey implacable frente a sus enemigos, celoso de su autoridad y que tiene la capacidad de mostrar crueldad, de provocar el miedo y, finalmente, de alternar entre rigor y clemencia (2012: 191-194). ${ }^{2}$

Desde esta perspectiva, el modelo de rey que el poema presenta es el correlato de la justificación de sus acciones: si las acciones del rey se justifican solo por la necesidad de pacificar el reino, entonces el rey se configura como rey justiciero y pacificador a través de la inclemencia que despliega en el cumplimiento de esa tarea; es decir, en el hecho mismo de que se muestre intransigente a la hora de enfrentarse a una nobleza que actúa anárquicamente. Así, el fin justifica los medios, motivo por el cual estos últimos no tendrían mayor relevancia en la construcción del modelo regio.

Sin embargo, esta configuración del rey, donde -más allá de la alternancia mencionada- se privilegia la inclemencia y hasta cierta "inhumanidad" (Rodríguez-Picavea, 2012: 193), pareciera entrar en contradicción con los consejos sobre el buen gobierno que el ayo le da al rey cuando este decide intervenir para controlar a los tutores. En efecto, dentro de los consejos vinculados a la política interna, el ayo le marca al rey un límite para el ejercicio de la justicia en relación con sus vasallos: "e teneldos a derecho/ con espada de justicia/ mas non vos vença el despecho/ nin vos fuerce la cobdicia" (PAO: estr.130). ${ }^{3}$

Como vemos, si bien la justicia es una de las virtudes que debe poseer el rey, el ayo no considera que la justicia sobre los vasallos deba ejercerse de forma inclemente, sino que, por el contrario, marca la necesidad de que haya un contrapeso: el rey debe impartir justicia, pero debe hacerlo de forma prudente y mesurada. Se delinea allí, entonces, un modelo de acción ejemplar: la templanza con los propios. ${ }^{4}$

En este sentido, habría una contradicción entre el modelo de rey propuesto por el ayo y la construcción del modelo de rey justiciero desplegada a lo largo del relato: mientras el modelo del ayo marcaría la necesidad de impartir justicia con prudencia y mesura, 
el poema mostraría un rey que imparte justicia de forma inclemente. Pero, dada esta contradicción, se hace necesario volver a interrogar el modelo de rey justiciero y pacificador que el poema construye y, por lo tanto, también la forma -correlativa- de justificar sus acciones.

Respecto de las justificaciones, Janin ha señalado que, en el Poema de Alfonso Onceno, a diferencia de lo que ocurre en La Crónica de Alfonso Onceno, las acciones y decisiones del rey no pueden justificarse siempre de acuerdo con conveniencias históricas o políticas, sino, como se trata de un poema épico, "estas deben enmarcarse dentro de la ética caballeresca de la poesía heroica" (2015: 126). ${ }^{5}$ Por eso, el poema recurre a la "distorsión tendenciosa de datos históricos" (2015: 123) para inscribir las acciones del rey en el marco de esa ética. Y en la misma línea, Mercedes Vaquero ha señalado que "cuando la realidad histórica acusa al rey de alguna mala acción, el poeta no duda en tergiversar los hechos o usar todo tipo de recursos literarios para suavizarlo" (1984: 306).

Podríamos decir, entonces, que el poema no considera que cualquier medio es válido para pacificar el reino, sino que, en cambio, pretende justificar las acciones del rey a través de la forma en la que estas acciones se presentan, es decir, al presentarlas como acciones adecuadas para un héroe épico. En otras palabras: el poema parece prestar especial atención precisamente a los medios a través de los cuales se da la pacificación del reino por parte de Alfonso XI. Y eso porque, de otro modo, las acciones del rey podrían aparecer como controversiales, al no tener un carácter intrínsecamente virtuoso en relación con la ética caballeresca e independientemente de los fines perseguidos.

Desde esta perspectiva, para pensar el modelo regio que el poema propone, creemos que sería necesario considerar principalmente cómo actúa el rey y, sobre todo, por qué actúa de una forma y no de otra en cada situación particular. Es decir que se trata de ver, no solo las decisiones puntuales que el rey toma frente a la nobleza (el asesinato o el perdón, por caso) y la forma en que la nobleza actúa, sino también el conjunto de la situación que lleva a esa acción: la forma de presentar los distintos conflictos que enfrenta el rey y el modo en que el rey toma las decisiones adecuadas para cada problema particular.

Por eso, en este trabajo nos proponemos una lectura detallada de la función de los consejos en los episodios más controversiales de la política interna: el casamiento con Constanza Manuel, el asesinato de don Juan el Tuerto, la ruptura del casamiento y la reconciliación con don Juan Manuel. Episodios que tomamos como particularmente controversiales no solo por la importancia de don Juan Manuel y don Juan el Tuerto en la Castilla de la época, sino sobre todo por motivos internos a la construcción de la obra: el poema otorga a los conflictos entre el rey y estos dos poderosos un tratamiento más extenso y detallado que al resto. Tal tratamiento atestigua de la dificultad de enmarcar estos conflictos dentro de los códigos de conducta que supone la ética caballeresca. Motivo por el cual podemos considerar los episodios mencionados (ligados indisolublemente a los conflictos entre el rey y los dos nobles) como particularmente controversiales precisamente en relación con esa ética.

En ellos observamos que el poema hace intervenir, sistemáticamente, uno o dos consejos. Esos consejos son de dos tipos: algunos apuntan a la mesura y otros a la intransigencia. Así, la hipótesis de este trabajo es que los consejos permiten presentar estas situaciones de conflicto con la nobleza bajo la forma de problemas relativos al ejercicio del gobierno. De ese modo, el poema pone de manifiesto las motivaciones y justificaciones que guían las decisiones tomadas por el rey frente a cada problema particular. A través de este mecanismo, entonces, se le atribuyen al rey cualidades virtuosas vinculadas a la toma de decisiones y el cumplimiento de los deberes regios que permiten adecuar su figura al modelo delineado por el ayo.
5. Cuando hablamos de épica no circunscribimos el término a la categoría más estricta de cantar de gesta. No obstante, como ya se ha demostrado largamente para el caso del Cantar de Mío Cid, los valores caballerescos no están divorciados del ideal heroico de los cantares de gesta. Y en el caso del Libro de Alexandre podemos hablar de un texto que hace convivir elementos de la épica y valores caballerescos. El Poema de Alfonso Onceno se nutre literariamente tanto del Cantar de Mío Cid como del Libro de Alexandre. Por otro lado, en cuanto a la relación entre crónicas y Poema de Alfonso Onceno puede verse Catalán 1953 y, mejor aún, Vaquero 1984. 
6. Cabe recordar la idea de Vaquero respecto de que el poema busca exponer una "doctrina de organización política o arte de gobierno" (1982: 138). Este trabajo apunta a especificar algunos aspectos de esa doctrina.

7. En efecto, Álvar Núñez dice que "los bandos partiredes/ rey señor, por este fecho/ e de Castiella seredes/ rey e señor con derecho" (PAO: estr.175).

8. El consejo del ayo completo es el siguiente: "Señor/ el que vos fue consejar / diovos consejo mejor/ que yo vos podría dar./ Las sospechas son muy malas/ e avedes a cuidar:/ ave que non tiene alas/nunca bien puede bolar;/ e bien los caballos/ sin pies non pueden andar:/ rey que non tiene vasallos/ nunca puede bien regnar./

E vos, rey de gran bondad,/ pues todos así están,/ con Constança (vós) casad,/ la fija de don Johán./ Ca de los reys castellanos/ viene de generación,/ de los condes saboyanos/ e de los reys de Aragón./ Por eso es gran bien e fiero/ si la por mujer tomades" (PAO: estr. 182-187)
En este sentido, el poema muestra un rey que sabe escuchar a sus consejeros para tomar la decisión más prudente, mesurada y justa según los distintos casos particulares que se le presentan. La imagen del rey justiciero y pacificador que diseña el poema es, entonces, correlativa de la mesura y la prudencia con que el rey resuelve los conflictos. Podríamos invertir la fórmula de la justificación señalada al comienzo: no es la pacificación interna la que justifica los medios, sino que el poema presenta las acciones del rey como intrínsecamente pacificadoras y justas, lo que justifica esas acciones.

A la vez, si este uso de los consejos permite exponer los motivos y justificaciones detrás de las decisiones del rey frente a los conflictos con la nobleza, entonces en la configuración del rey justo y pacificador es posible leer la perspectiva del poema respecto de la política interna del rey: el modelo de fortalecimiento del poder regio propuesto y su concepción del ejercicio de la justicia. ${ }^{6}$

\section{El casamiento con Constanza Manuel: concentración o expansión del poder}

El primer conflicto al que se enfrenta el rey es el de la conjura de don Juan Manuel y don Juan el Tuerto. Para la resolución de ese conflicto, el poema hace intervenir dos consejos iguales que tienen, sin embargo, distintos motivos como fundamento.

Álvar Núñez aconseja al rey casarse con Constanza Manuel para romper la alianza entre su padre y don Juan el Tuerto porque, si los nobles se alzaran contra el rey, "non vos dexarán regnar/ nin aver palmo de tierra" (PAO: estr.171). Así, le asegura que casarse "será muy buen recabdo" (PAO: estr.174). Lo que propone Álvar Núñez es, por lo tanto, usar la astucia para desarmar la conspiración como precaución, pero también para concentrar el poder. ${ }^{7}$ El rey acepta el consejo, pero el Poema se ocupa de señalar que lo hace "sin su grado" (PAO: estr.176).

Entonces, para refrendar el consejo del noble, el rey se dirige al ayo. Pero lo que el rey le plantea al ayo no es lo mismo que Álvar Núñez le había planteado a él. Como vimos, lo que había esgrimido el noble era el problema de qué hacer ante la amenaza que suponía la conspiración. En cambio, el rey, después de exponer cómo los tutores complicaron su reinado durante la minoridad y luego se juntaron para ayudarse mutuamente ante el "recelo" (PAO: estr.179) de que impartiera justicia contra ellos, le dice al ayo que "Don Johan si me bien quier/ esto non lo sé sin dubdança/ tomar quiero por mujer/ su fija doña Constanza" (PAO: estr.181). Es decir, le plantea un conflicto, no solo vinculado a la conjura, sino vinculado a la sospecha sobre la deslealtad, o la confianza en la lealtad de sus vasallos.

Por eso, el ayo valida el supuesto consejo de Álvar Núñez. Pero, dado el planteo del rey, la motivación para validarlo es otra. La respuesta del ayo ante esta particular formulación es que "las sospechas son muy malas" porque "rey que non tiene vasallos/ nunca puede bien regnar" (PAO: estr.184). ${ }^{8}$ Si para Álvar Núñez el casamiento apuntaba a usar la astucia para ser precavido y desarmar la conjura, para el ayo se trata de tener confianza en la lealtad y ser conciliador para garantizar un buen reinado.

De este modo, la diferencia entre la precaución que supone el casamiento para Álvar Núñez y la advertencia contra las sospechas que aconseja el ayo pone en evidencia otra serie de diferencias. En estos dos motivos hay, no solo dos modelos de consejeros contrapuestos, sino además dos perspectivas distintas sobre la relación que debe mantener el rey con sus vasallos. Álvar Núñez, que encarna el modelo de consejero controvertido, apunta a la imposibilidad de reinar con vasallos rebeldes. El ayo, paradigma del buen consejero, alude a la imposibilidad de reinar sin vasallos leales. 
Podríamos decir que, mientras Álvar Núñez ve a los otros vasallos como obstáculos, en tanto posibles aspirantes a ocupar su lugar de privado, el ayo los ve como complementos del rey. En este sentido, el dilema que se le plantea al rey en boca de sus dos consejeros supone una tensión entre la imposición de la autoridad por la fuerza (el engaño destinado a erosionar el poder del otro) y la pacificación, es decir, entre dos modelos de fortalecimiento del poder regio: un modelo político de concentración del poder y otro de expansión del poder.?

Así, lo que el ayo señala cuando observa que "Rey que non tiene vasallos/ nunca puede bien regnar" es, en definitiva, lo mismo que había advertido al comienzo. No solo el rey depende de sus vasallos para reinar (dado que, en efecto, los necesita para la guerra contra el infiel y para desempeñar funciones en la corte), sino también que un buen rey necesita garantizarse su lealtad mediante la conciliación. Con ese objetivo sería necesario que, en los términos del planteo del ayo, "non vos vença el despecho" por la conjura y los conflictos durante la minoridad: es decir, tener confianza en la lealtad intrínseca de los nobles, más allá de conflictos coyunturales. Se trata, no solo de lo necesario para reinar, sino también de los deberes de un buen rey en relación con sus vasallos.

El poema presenta, entonces, dos consejos iguales. Pero esos dos consejos tienen fundamentos distintos. Con la reticencia del rey a la aceptación del primer motivo y su aceptación del consejo a raíz del segundo, el poema jerarquiza un motivo por sobre el otro. Casi como si los dos consejos respondieran a acontecimientos distintos. De este modo, se exponen los fundamentos de la decisión del rey y sus cualidades en la toma de decisiones. Su imagen se configura como la de un rey que, en vez de decidir su curso de acción en política interna movido por la intransigencia frente al despecho (disolver el poder ajeno para incrementar el propio), se decide movido por la prudencia y la mesura ante las sospechas. De ahí se desprende que el rey, más que controlar o subordinar a sus vasallos por malicia e intereses egoístas, decide confiar en su lealtad y obra para garantizarla. Del mismo modo, se deja claro que lo que mueve al rey no es su deseo de imponer su autoridad, sino su anhelo de reponer la paz interior: si la pacificación no deja de ser un justificativo de la acción del rey, esta no aparece como una justificación independiente de los medios a los que el rey recurre para lograrla, sino condensada y expresada en esos mismos medios.

\section{El asesinato de don Juan el Tuerto: dos derechos enfrentados}

El segundo conflicto al que se enfrenta el rey es el que se da con don Juan el Tuerto. Como en el caso anterior, el poema presenta una situación dilemática que será, sin embargo, distinta de la precedente: el caso de don Juan el Tuerto es tratado como un problema desligado de la cuestión de la conjura con don Juan Manuel.

Así, según relata el poema, los vasallos del rey le aconsejan matar a don Juan el Tuerto porque -le advierten- si no, "regnar nunca vos podredes" (PAO: estr.200). Los privados apoyan el consejo de los vasallos y van a buscar al noble para pedirle que vaya a Toro a encontrarse con el monarca. El noble responde que necesita que el rey lo asegure, por temor de la ira regia. Entonces, un privado aconseja al rey asegurar al noble, dado que "quien non segura, non prende" (PAO: estr.210). Eso ocurre y el Tuerto acepta marchar hacia Toro para encontrarse con el monarca.

El problema es que, cuando el Tuerto llega al encuentro con el rey, se humilla ante él y explica su conducta, desviada a los ojos del monarca, como motivada por el objetivo de "onrar el mi estado" (PAO:estr.217), lo que remite a un principio de la ética nobiliaria por el cual el noble tiene como deber conservar su estado e, incluso, acrecentarlo
9. La concentración y la expansión del poder son dos formas distintas de fortalecimiento del poder regio.

La diferencia es señalada por Arias Guillén (2012: 25). La concentración supone la subordinación de la nobleza. En cambio, la expansión del poder supone su integración al bando regio. Esa integración es posible por una confluencia de intereses entre el rey y la nobleza. El fortalecimiento del poder regio durante el período de Alfonso XI se habría dado, según Arias Guillén, bajo esta última modalidad. Si bien seguimos esta perspectiva, el mismo Arias Guillén recuerda en su estudio que historiadores anteriores, como De Moxó, proponían un modelo de concentración del poder y enfrentamiento con la nobleza. 
10. De hecho, en una escena que se da después de terminado el conflicto con los nobles, don Juan Manuel pide perdón y se justifica remitiendo al mismo principio "Por onrar el mi estado/ en muchas cosas pequé" (PAO: estr. 1284).

11. Como bien señala Hilda Grassotti en su canónico artículo sobre la ira regia en Castilla y León "la descarga de la ira regia se realiza al margen de todo proceso legal" (1965: 56).

12. No está de más insistir en que trabajamos con el relato poético que cuenta la historia desde un punto de vista épico. Pues, tal como puede leerse en la Crónica de Alfonso XI (sin que esto implique que adjudiquemos a la crónica una imparcialidad y rigor histórico de los que evidentemente carece), el rey no solo hizo matar a don Juan el Tuerto, sino que además se quedó con sus bienes, desentendiéndose, además, de sus herederos.
(Orduna, 1982: 244). El rey aplaza la resolución del caso para el día siguiente y pide que le aconsejen qué hacer con el noble. A pesar de todo, el rey no puede castigarlo directamente porque ha pedido su perdón, pero tampoco puede perdonarlo porque: "A mí todos miedo han/ tiénenme por natural/ salvo si es don Johán/ que quiso siempre mi mal" (PAO: estr.230), es decir, porque lo considera desleal.

Por eso, en el marco de esta secuencia narrativa el pedido de consejo señala un dilema: ejercer o no sobre el noble el derecho a la ira regia que la traición habilita. En efecto, por un lado, aplicar ese derecho sin considerar el pedido de perdón del noble supondría (digamos: desde el marco de la ética caballeresca) un acto de inclemencia desmesurada. Y, por el otro, no aplicar ese derecho implicaría reconocer la preeminencia del principio ético nobiliario de acrecentamiento del estado (esgrimido por el Tuerto como justificación de su conducta) sobre la obligación de servicio al rey cuya vulneración habilita el ejercicio de la ira regia. Por ende, el dilema consiste en un enfrentamiento entre dos derechos: el principio ético nobiliario mencionado y la obligación de servicio al rey. ${ }^{10}$

Así, el rey no desconoce la justificación del noble y la ética que la rige, sino que, por el contrario, cuando pide los consejos tiene en cuenta lo que le dice. De ese modo, con el pedido de consejo el poema construye un rey justo y mesurado: incluso cuando la traición deja al noble sin garantías frente a la ira regia, el rey no aplica intempestivamente su derecho, sino que, como escuchó el pedido de perdón del noble y su justificación, busca, por medio de los consejos, tomar la decisión correcta en el marco de una suerte de proceso judicial improvisado al que el propio noble se somete y que sustituye un verdadero proceso judicial del que la institución de la ira regia podían prescindir. ${ }^{11}$

Los consejos serán dos: uno de Álvar Núñez y otro de un privado. Álvar Núñez aconseja encarcelarlo y tomar sus tierras. El rey, en principio, acepta para-como dice- hacer justicia y dar un castigo ejemplar frente al resto de sus vasallos. Pero el privado señala que, si lo encarcela, cuando quede libre, el Tuerto se vengará en la persona del rey. Y añade, además, que el noble tiene también pretensiones sobre el reino de León. De esta manera, aconseja matarlo porque "Si lo, señor, non matades/ non regnaredes un año" (PAO: estr.241). El rey entonces cambia de opinión y "sentencia" (PAO: estr. 242 ), finalmente, que maten al noble.

De este modo, mientras el primer consejo se centra en un castigo que apunta a disminuir el poder ajeno al quitarle las tierras y presupone, por lo tanto, la concentración del propio, el segundo se centra en los peligros de la traición y la ambición del Tuerto. Por eso, el contraste entre los dos consejos permite transformar la apreciación que el lector tendría sobre la decisión. Es decir, si en una lectura rápida, esa apreciación podría hacer parecer al rey inflexible, al sopesar un consejo que apunta a concentrar el poder frente a otro que advierte contra los peligros de la deslealtad, la decisión puede calificarse de prudente. Ese contraste permite mostrar, precisamente, que el rey no toma la decisión con el objetivo de disminuir el poder ajeno e incrementar el propio, sino de pacificar el reino frente a las peligrosas ambiciones de uno de los nobles más poderosos. ${ }^{12}$

El hecho mismo de que se muestre primero el impulso del rey de seguir el consejo de Álvar Núñez y luego su cambio de opinión al escuchar al segundo consejero, marca precisamente que el rey controla sus impulsos y ejerce la prudencia en función de la pacificación. Y si ese impulso estaba vinculado a la voluntad de dar un castigo ejemplar, el control del impulso marca que lo prioritario no es intentar imponer la autoridad del rey por medio de un golpe de fuerza inclemente, sino el cuidado del bien común. 
En definitiva, podríamos decir que el rey termina por ejercer su derecho a la ira regia frente a un noble que ha jerarquizado el acrecentamiento de su estado sobre el servicio al rey, pero solo después de escuchar al noble y recurrir a los consejos en un gesto de prudencia y mesura. Si el dilema del rey era ejercer o no el derecho a la ira regia con las consecuencias respectivas, estas actitudes del rey nos dan la pauta de que la justicia se concibe, no como la reacción inclemente frente a la nobleza díscola sino como el ejercicio racional -mesurado y prudente- de la toma de decisiones. El rey es justo porque muestra mesura y prudencia incluso cuando ejerce su poder de modo enérgico para pacificar el reino. Pero también porque contempla los derechos de los nobles y el punto de vista de su ética. Y, de hecho, si vamos un poco más allá, el rey no optaría por imponer su autoridad por medio de la confiscación de bienes frente a la voluntad nobiliaria de conservar el estado, sino que lo que evita hacer es precisamente afrentar los principios de la ética nobiliaria para mostrar que se mata al noble, no como acción ejemplificadora contra quienes se aferren a esa ética, sino por la protección del reino en función de su pacificación. ${ }^{13}$

\section{Ruptura y reconciliación con don Juan Manuel: deber de la ruptu- ra y venganza en el perdón}

Sin embargo, en una escena posterior veremos al rey romper el casamiento con Constanza y desatar inevitablemente un conflicto con don Juan Manuel. En efecto, después de la muerte de don Juan el Tuerto, los consejeros del rey se alegran y le aconsejan la ruptura con Constanza Manuel. Entonces le dicen que, después de intervenir contra uno de los bandos involucrados en la conjura de los nobles, "ya un bando es partido", se encuentra "bienandante" y se ha vuelto más "temido" que antes (PAO: estr. 249). Ante el cambio, le aconsejan no casarse con Constanza "Ca la Eglesia, nuestra madre/ tal casamiento non ama" (PAO: estr.251). Correlativamente, le indican que, ahora que mató al Tuerto, puede "casarse" y "ser de oy más temido" (PAO: estr. 252). Motivo por el cual el consejo es dejar a Constanza Manuel y casarse con doña María de Portugal: optar por la hija de un rey.

Como vemos, el cambio de situación justifica el cambio de consejo: ya no se trata de una finalidad impuesta por la necesidad de disolver la conspiración o de conciliar con los nobles, sino de hacer lo que corresponde a su estado en acuerdo con los preceptos de la Iglesia. De ahí que se ligue el fin de la conspiración a la posibilidad de "casarse". Es decir, de hacerlo acorde a su estado: tener un matrimonio legítimo, no viciado por un parentesco cercano, y con la hija de un rey. ${ }^{14} \mathrm{Y}$ es interesante notar que todo el consejo está pensado en función de la mirada ajena: se trata de cuan temido era el rey antes y después de la muerte de don Juan el Tuerto, y cuan temido puede ser después del matrimonio. Es en función de esa mirada que se le dice al rey lo que debería hacer.

En ese sentido, el matrimonio se aconseja como un signo doble. Por una parte, en tanto matrimonio legítimo, es un signo de la propia sujeción del rey a la ley divina: si bien el rey encarnaba la justicia en la tierra, para que su gobierno no se convirtiera en tiranía, era necesaria esa sujeción (Nussbaum, 2006: 18). Y, por otra, en tanto matrimonio con la hija de un rey, se trata de un signo de la jerarquía que lo habilita a reinar acrecentando su poder y el de su linaje. Así, como lo que está en juego es la mirada de los otros, lo que los consejeros le piden al rey es que se legitime frente al reino mediante ese signo doble, al actuar como debe actuar un rey justo por oposición a un rey tirano: al actuar de esta forma, el rey podría "ser más temido". Por lo tanto, este "temor" del que hablan los consejeros no remitiría al "miedo" que resulta del "espanto de premia" ejercido por el tirano (digamos: del amedrentamiento producido
13. Planteamos esta hipótesis porque, como ya mencionamos, en la Crónica, después de matar al noble, el rey confisca los bienes de don Juan. Así, el ama de la hija del noble huye con la niña por temor a represalias y la madre de don Juan el Tuerto es obligada a venderle al rey las tierras que le correspondían por herencia. El Poema omite estos detalles porque "suponen intereses económicos y políticos que traen consecuencias sobre sus bienes y las mujeres indefensas de su familia" (Janin, 2019: 129). En cambio, "solo nos es dado inferirlos de manera general del consejo que da Álvar Núñez" (ibídem). De este modo, la escena podría sugerir que el rey evita ceder al impulso de confiscar los bienes del Tuerto como forma de castigo. Pero, si nos atenemos a las explicaciones que da Grassotti siguiendo Las Partidas, la ira regia suponía castigar la traición con muerte, mientras que la confiscación de bienes o el exilio se reservaban para delitos considerados menores como los daños a la tierra del rey ('malfetrías') o los disturbios ('asonadas'), pues "al privarlo de sus honores, tierras, soldadas y bienes el rey reducía al magnate altivo y poderoso a la impotencia" (1965: 96). Es decir que el poema parece justificar la aplicación de un castigo mayor como modo de preservar el honor nobiliario, de manera de justificar moralmente ese castigo que, en los términos en los que es expuesto, apunta a priorizar la protección del reino sobre la disminución del estado del noble.

14. Si bien se hacen primar las razones religiosas, las razones políticas (una alianza con Portugal) fueron, desde luego, las más importantes, a tal punto que permitieron desentenderse del hecho de que María de Portugal también era su prima. Pero, desde luego, un poema laudatorio del rey no tiene por qué hacerse cargo de esto. Para el tema de la dispensa papal para el casamiento con María puede verse Echevarría Arsuaga 2017: 171 
15. En palabras de Foronda: “mientras que el temor es producto del amor, el metus/miedo es producto del espanto, "espanto de premia" (Foronda, 2007: 2). Así, según este autor, el poder regio en la Edad Media se definiría por dos polos "por una parte, un polo positivo, el del rey/amor/temor, por otra, un polo negativo o desviado, el del tirano/espanto/miedo" (ibidem).

16. En la misma línea, este sentido de la palabra "temor" -como resultado del amor- explica el motivo por el cual los consejeros del rey se alegran luego de la muerte de don

Juan el Tuerto y le dicen a Alfonso que ahora es más "temido" que antes: frente a don Juan el Tuerto, el rey ha cumplido su deber como rey justo y, por lo tanto, ha dado un primer paso para mostrarse frente

al reino como tal y garantizarse su amor. De hecho, como mostramos en el apartado anterior de este trabajo, el poema presenta el asesinato del Tuerto, no como una reacción inclemente del rey destinada a imponer su autoridad, sino como una decisión prudente y mesurada en función de la pacificación del reino, es decir, del bien común. Por otro lado, si se considerara la alegría de los consejeros del rey un gesto de cinismo (alegría por el incremento del miedo al rey

y de su poder), no se entendería la necesidad que tienen estos con-

sejeros de justificar la ruptura con

Constanza mediante los preceptos eclesiásticos y la posibilidad de tener un matrimonio legítimo: el consejo podría haber sido otorgado con el mismo cinismo.

17. Recordemos que el rey es todavía niño (como lo señala la profecía sobre la muerte del Tuerto) y que, en ese sentido, puede entenderse como necesario el hecho de tener que legitimarse.

18. En efecto, más adelante, don Juan Manuel ataca Toledo y, en ese momento, el poema dice que "Quando el rey esto oyó/ ayuntó la su conpaña:/ por las tierras se salió/ como el león con saña" (PAO: estr. 298). Es con esta "saña" que el rey se dirige a Escalona para cercar al noble. por el golpe de fuerza), sino al "temor" que resulta del amor al rey (Foronda, 2007: 2). ${ }^{15}$ En ese sentido, el consejo no apunta a la imposición de la autoridad del rey, sino, en este contexto, a garantizarse el amor del reino. ${ }^{16}$

En esta línea, la justificación de la ruptura no es simplemente la oposición de la Iglesia al matrimonio, sino que en la aceptación de esa oposición se cifra una actitud virtuosa del rey. ${ }^{17}$ De este modo, lo que justifica la acción del rey es el hecho de escuchar a sus consejeros para demostrar que puede regir -y pacificar- el reino "con espada de justicia" (PAO: estr.130), es decir, sin aplicar una política del espanto: sin ser un tirano.

Ahora bien, después de este consejo y de consumar el arreglo del nuevo matrimonio, el rey ordena la cárcel para don Juan Manuel o, en su defecto, la muerte. Lo curioso es que el poema no considera necesario dar motivos para esa orden: si antes el ayo había advertido contra las sospechas y, luego de que el rey optara por confiar en la lealtad del noble, las relaciones entre los dos poderosos se encontraban-según narra el poema- en buenos términos, en este episodio se presupone directamente que don Juan Manuel es un noble desleal. Y eso porque, ahora que la situación ha cambiado y el rey debe actuar acorde a su estado y los preceptos eclesiásticos, se considera implícitamente que debe también castigar la deslealtad del noble que antes no quiso castigar por confiar -más allá de conflictos coyunturales- en su lealtad intrínseca.

Podríamos decir, entonces, que en este momento el rey muestra la fortaleza y justicia necesarias para enfrentarse a sus enemigos, en tanto esa fortaleza es también una virtud del héroe épico. Pero esa muestra de fortaleza no es desmesurada e inclemente, porque, por el modo en que se narra el prendimiento de don Juan Manuel, aparece bajo la forma de una autoridad jurídica.

En efecto, al contrario de lo que ocurrirá más adelante (cuando el noble se decida a hacer la guerra contra el rey), Alfonso no decide prender al noble movido por la "saña" (PAO: estr.298). ${ }^{18}$ En cambio, según narra el poema, los consejeros del rey, después de arreglado el casamiento con doña María de Portugal, se retiran a un lugar apartado y, "en poridad" (PAO: estr. 261), ordenan el prendimiento del noble a través de cartas selladas "con sello del rey" (ibidem). A lo que agregan que, solo en caso de no poder prenderlo, "luego lo matassen" (PAO: estr. 263). La orden se da, por lo tanto, sin que medie la palabra regia. Esa palabra se reemplaza por el sello: marca de la legalidad del prendimiento y del aval que Alfonso XI le otorga a la orden en tanto figura de autoridad. A la vez, el hecho de que las cartas se redacten en secreto refuerza este aval al sugerir que el rey delega la orden en sus consejeros de mayor confianza: aquellos que, dentro de la corte, acceden a la información que el resto no debe saber para que no se filtre antes de tiempo. Así, esta escena de delegación de una orden ligada a la justicia permite exponer la firmeza de la autoridad del rey en tanto autoridad jurídica y mostrar que detrás de esa orden no hay ningún tipo de sentimiento particular contra el noble rebelde: el reemplazo de la palabra regia por el sello, la correlativa dimensión legal del proceso y el hecho de que la muerte de don Juan Manuel se ordene solo en caso de no poder prenderlo marcan que, para el monarca, se trata únicamente de garantizar la justicia en el reino. Por eso, la actitud de Alfonso XI responde, en este momento, a la imagen de un rey justo que, así como debe exponer los signos del límite de su poder y los signos de su jerarquía, debe también, ante el cambio de situación, ejercer justicia con la mesura y la templanza que suponen el respeto de los procedimientos jurídicos.

Sin embargo, es claro que, como dijimos, hay una incongruencia narrativa: antes, en el momento de la unión con Constanza Manuel, el rey había optado por confiar en don Juan Manuel, pero ahora se presupone que es desleal. En esa incongruencia se cifraría una tensión entre la imagen del rey pacificador que el poema había configurado hasta 
acá y la necesidad de mostrar la imagen de un rey éticamente justo en relación con el código caballeresco: la ruptura del casamiento solo podía derivar en un conflicto. La contradicción resultante parece evidenciar, entonces, que la justificación es endeble: acaso aparece aquí un resto polémico de la historia que, dada la cercanía temporal de los hechos, el poema no puede trastocar demasiado.

Tal vez precisamente por esta contradicción, el poema, en este caso, haya cambiado de estrategia, al hacer intervenir solo un consejo y no dos: el uso de un único consejo permitiría presentar la actitud del rey como un deber moral -el de ser justo- donde no hay otra opción. ${ }^{19}$

En esta línea, los dos consejos que antes se contraponían en el marco de una misma escena, ahora vuelven a contraponerse, pero distanciados en el tiempo del relato: si el conflicto con don Juan Manuel se abre con este consejo de inclemencia, se cierra con un consejo de mesura. Sobre el final, después de que (de acuerdo con la versión que propone el poema) don Juan Manuel lo enfrente deslealmente numerosas veces, una señora le dice al rey que el noble ya está viejo y le pide que lo perdone. El rey acepta, entonces, otorgar el perdón.

Así, ese consejo final permite mostrar un rey magnánimo en su capacidad de perdonar la deslealtad del noble rebelde y, al mismo tiempo, evitar que la reconciliación se presente como una muestra de debilidad del rey, pues los versos que cierran la escena orientan la lectura ejemplar en esa dirección: "Así se sopo vengar/ este rey de gran altura [...]" (PAO: estr.599). Como vemos, los versos marcan que el perdón es al mismo tiempo una forma de venganza digna de elogio. Pero cabe entonces preguntarse: ¿en qué sentido podrían ser compatibles el perdón y la venganza?

Si se toma la escena aislada de la totalidad del conflicto, el sentido de la palabra "venganza" contradice el perdón del rey. En cambio, si leemos la escena en el marco del conflicto más amplio, esa idea de "venganza" podría leerse vinculada a la subordinación del noble después de las injusticias que él mismo reconoce. Por eso mismo, el perdón sería, a su vez, una muestra de la preeminencia del rey: ya no una debilidad. ${ }^{20}$ De ese modo, la idea de venganza podría ser compatible con la idea de perdón: la venganza del rey no implicaría necesariamente la ejecución de la ira regia, sino mostrar la propia preeminencia bajo una forma de fortalecimiento del poder regio donde se prioriza la expansión del poder sobre su concentración, al reintegrar a don Juan Manuel al bando regio en una posición claramente subordinada. ${ }^{21}$

En definitiva, la relectura ejemplar de la escena y de la totalidad del conflicto a la que invitan estos versos impondría una perspectiva general sobre el conflicto: la de un rey que buscó vengarse por las deslealtades, pero que lo ha hecho con mesura, incluso en los casos de aplicación de una justicia drástica. Por eso, en algún punto, la contraposición del consejo que abre el conflicto con el consejo que lo cierra sugeriría además una perspectiva particular sobre esos dos episodios de la lucha entre don Juan Manuel y Alfonso XI: la idea de que, en el momento de la ruptura con Constanza Manuel, el rey debió mostrar su fortaleza, pero supo ser mesurado y otorgar el perdón cuando el noble, ya viejo, reconoció sus culpas. Tal vez así el poema marcaría que el objetivo fue siempre pacificar el reino y reintegrar a la nobleza al bando regio, pero no eliminarla. ${ }^{22}$

\section{Conclusión}

La contemporaneidad del Poema de Alfonso Onceno respecto de los hechos narrados impide recurrir a la alteración de la realidad histórica para la construcción de la distancia épica. Por eso, persisten en el poema una serie de hechos susceptibles de ser vistos como
19. En efecto, el mecanismo del doble consejo no aparece solo en los casos analizados, sino también en otros (ya no directamente ligados a la política interna) que podrían ser problemáticos en relación con el modelo de héroe épico. Así, lo podemos ver reaparecer en otras dos ocasiones controversiales: cuando el rey se encuentre en aprietos en el cerco de Gibraltar (y termine, de hecho, por pactar con el rey de Granada) y cuando tenga que decidir si recurrir o no, para defender Tarifa, a la ayuda del rey de Portugal; ayuda a la que efectivamente recurre.

20. De hecho, Arias Guillén señala que, en el período de Alfonso XI, la política pactista que antes podía ser considerada una debilidad, era ya una virtud (2012: 202-203)

21. Esta necesidad de mostrar el perdón como forma de venganza supone un dilema: perdonar al noble a riesgo de mostrarse débil o no perdonarlo a riesgo de mostrarse inclemente. Recordemos que, en sus consejos, el ayo mismo le dice al rey que sea "mesurado" con el "vencido". Así, el dilema es similar al que se le había presentado al rey en el caso de don Juan el Tuerto. Pero en este caso se presenta bajo una forma simétricamente inversa: en el caso de don Juan el Tuerto el problema era ejercer o no la ira regia, aquí se trata de perdonar o no al noble. Por eso, si antes el poema había mostrado el ejercicio de la ira regia como una decisión mesurada y prudente en función de la pacificación, en este caso el poema presenta el perdón como una forma de venganza.

De ese modo, al igual que en el caso de don Juan el Tuerto, la preeminencia del rey y de sus prerrogativas se mantiene, al tiempo que se destaca su templanza.

22. En esa perspectiva, el Poema estaría en la línea de la Gran Crónica (Janin, 2011: 14). 
23. Foronda ha señalado que la cronística regia del siglo XIV es un género "políticamente fusional", en la medida en que "integra otros elementos de un discurso, de una ideología y de un sentir más bien aristocráticos, no siempre para construir una mera oposición, y menos aun cuando sus principales artífices, Fernán Sánchez de Valladolid y Pedro López Ayala, son miembros destacados de la pujante nobleza de servicio" (2007: 5). Podríamos decir que el poema se inscribe en este contexto discursivo donde "se trata de elaborar, desde ese presente de redacción y convivencia por fin sosegada, de manera retrospectiva pues, la historia de los compromisos vigentes" (ibídem). De esta manera, la obra integra también una visión sobre la ética nobiliaria y sobre los conflictos jurídicos. controversiales. Sin embargo, en vez de alterar la realidad histórica, el poema recurre a "un proceso más sutil de distorsión que opera en el nivel de la interpretación del hecho histórico más que en la veracidad del hecho en sí" (Janin, 2019: 18).

En efecto, por medio de los consejos, el poema construye un relato narrado desde la perspectiva regia. Esa perspectiva se manifiesta en las motivaciones de las decisiones que el rey toma frente a cada dilema que se le presenta. Desde este punto de vista, el poema presenta la imagen de un rey que, sin dejar de mostrar su fortaleza y preeminencia frente a la nobleza rebelde, toma decisiones mesuradas, prudentes y justas. Por eso, más que justificar a priori las acciones del rey a través de la pacificación, el poema disputa, a través del uso de los consejos, el sentido de sus acciones para mostrar que, en cada caso particular, se adecúan a la ética dentro de la cual se piensa el modelo de rey justo y pacificador.

Así, el modelo de rey pacificador que propone el poema supone, a la vez, un modelo de fortalecimiento del poder regio, es decir, un modelo de los medios que el poema considera más adecuados para lograr la pacificación del reino. El uso de los consejos en la configuración del rey pacificador permite mostrar que Alfonso XI no pretendió someter a la nobleza, sino garantizarse su lealtad mediante la conciliación y proteger al reino. En ese sentido, el poema evita presentar el fortalecimiento del poder regio como una forma de concentración del poder y de imposición por la fuerza de la autoridad regia para presentarlo, en cambio, bajo la forma de una expansión del poder marcada por la actitud conciliadora y la búsqueda de reintegrar a la nobleza rebelde al bando regio. El texto sugiere, así, que el monarca buscó redirigir los esfuerzos de los nobles hacia el punto en el que sus intereses podían coincidir con los del rey, es decir, hacia la lucha por la Reconquista. El modelo de rey pacificador es, entonces, un modelo pactista: el rey pacificador ejemplar es un rey conciliador.

Por otro lado, en lo que respecta a la concepción de la justicia, los casos analizados muestran que, en la toma de decisiones por parte del rey, el poema parece tener en cuenta, no solo una determinada visión de la ética nobiliaria, sino también los conflictos jurídicos suscitados por la confrontación entre la perspectiva regia y esa ética. ${ }^{23}$ Por eso, si, como decíamos al comienzo, en el poema la concepción de la justicia es correlativa de la mesura y la prudencia ejercida para resolver los conflictos con los nobles, ahora podríamos decir que la mesura y la prudencia del rey en el ejercicio de la justicia se vinculan al respeto de la ética nobiliaria, lo que permite darle cierta dimensión conciliadora al ejercicio de la justicia: la ira regia nunca se aplica de forma intempestiva y, así, el poema la presenta como prerrogativa del rey que no impide necesariamente tener en cuenta los derechos de los nobles.

De este modo, en una hipótesis más arriesgada, podríamos decir que el poema buscaría imponer, de forma conciliadora, un orden jurídico ligado a la perspectiva regia. Una estrategia que, de hecho, habría sido la que puso en marcha Alfonso XI, quien habría cedido artificiosamente a ciertas reivindicaciones de la nobleza para imponer el derecho regio: como señala Iglesia Ferreirós, el Ordenamiento de Alcalá de 1348 (fecha más probable de composición del Poema de Alfonso XI) reconoce aspectos del derecho señorial para enmarcarlos "dentro del marco trazado por la legislación regia" (1977: 155).

Desarrollar esta hipótesis requeriría contrastar el modo en que se presenta el ejercicio de la justicia en el poema como ejercicio condicionado por la configuración de un rey caballeresco con la forma en que se presenta ese ejercicio en la Crónica de Alfonso $X I$, donde no hay tal condicionamiento. En otras palabras, se trataría de pensar las operaciones por medio de las cuales el Poema de Alfonso XI reinterpreta el ejercicio de la justicia tal como se presenta en la Crónica para adecuarlo al modelo de rey caballeresco. Dejamos ese contraste para futuros trabajos. 


\section{Dibliografía}

" Arias Guillén, F. (2012). Guerra y fortalecimiento del poder regio en Castilla. El reinado de Alfonso XI (1312-1350). Madrid: Ministerio de Defensa.

»Catalán Menéndez-Pidal, D. (1953). Poema de Alfonso XI: fuentes, dialecto, estilo. Madrid: Gredos.

"Echevarría Arsuaga, A. (2017). “Redes Femeninas En La Corte Castellana: María De Portugal (1313-1357)”. La corónica: A Journal of Medieval Hispanic Languages, Literatures, and Cultures, 45, 2, 165-189.

»Foronda, F. (2007). "El miedo al rey. Fuentes y primeras reflexiones acerca de una emoción aristocrática en la Castilla del siglo XIV”. e-Spania, IV. En: https:// journals.openedition.org/e-spania/2273; obtenido el o8/03/2020.

» Grassotti, H. (1965), “La ira regia en León y Castilla”. Cuadernos de Historia de España, XLI-LXII, 5-135.

" Iglesia Ferreirós, A. (1977). "Derecho municipal, derecho señorial, derecho regio", Historia. Instituciones. Documentos, IV, 115-198. En: http://institucional.us.es/revistas/historia/04/05\%20iglesia\%2oferreiros.pdf; obtenido el 08/03/2020.

》 Janin, E. (2015), “La construcción de Alfonso XI como héroe épico en el Poema de Alfonso Onceno: el caso del asesinato de don Juan el Tuerto". Letras, 72, 121132. En: https://repositorio.uca.edu.ar/bitstream/123456789/3791/1/construccion-alfonso-xi-heroe-epico.pdf; obtenido el 08/03/2020.

" Janin, E. (2011) "El rey y la nobleza en el Poema de Alfonso Onceno y la Gran Crónica de Alfonso XI: construcción ejemplar del rey en el relato del proceso de pacificación interna de Castilla". Hispanic Research Journal, 12, 3-17.

» Janin, E. (2019) “Una vez más sobre el género del Poema de Alfonso Onceno: ¿historiografía en verso o épica?”. Estudios de historia de España, 21, 1-25. En: http://erevistas.uca.edu.ar/index.php/EHE/article/view/2096/1946; obtenido el o8/03/2020.

"Nieto Soria, J. M., (1989), "Los fundamentos mítico-legendarios del poder regio en la Castilla bajomedieval”. En: Jean-Pierre E. (ed.), La leyenda: antropología, historia, literatura. Actas del coloquio celebrado en la casa de Velázquez (10/11 de noviembre 1986). Madrid: Casa de Velázquez - Universidad Complutense, 55-68.

»Nussbaum, F. (2006), “El pensamiento político en el Poema de Alfonso XI: la relación Monarquía-Iglesia”. Boletín Hispánico Helvético, 7, 5-44.

»Orduna, G. (1982). “El Libro de las armas: clave de la 'justicia' de don Juan Manuel". Cuadernos de Historia de España, 67-68, 230-268.

»Paquette, J. M. (1988) “L'épopée”. Typologie des sources du Moyen Âge occidental, fasc. 49. Turnhout, Bélgica: Brepols, 17-35.

»Rodríguez-Picavea, E. (2012). “Ideología y legitimación del poder en la Castilla del siglo XIV. La imagen regia en el Poema de Alfonso XI". Medievalismo, 22, 185-216. En https://revistas.um.es/medievalismo/article/view/164381/142951; obtenido el 08/03/2020

"Vaquero, M. (1984). El “Poema de Alfonso Xl”: ¿¿crónica rimada o épica? Michigan: UMI.

"Victorio, J. (ed.) (1991). Poema de Alfonso Onceno. Madrid: Ediciones Cátedra. 
